
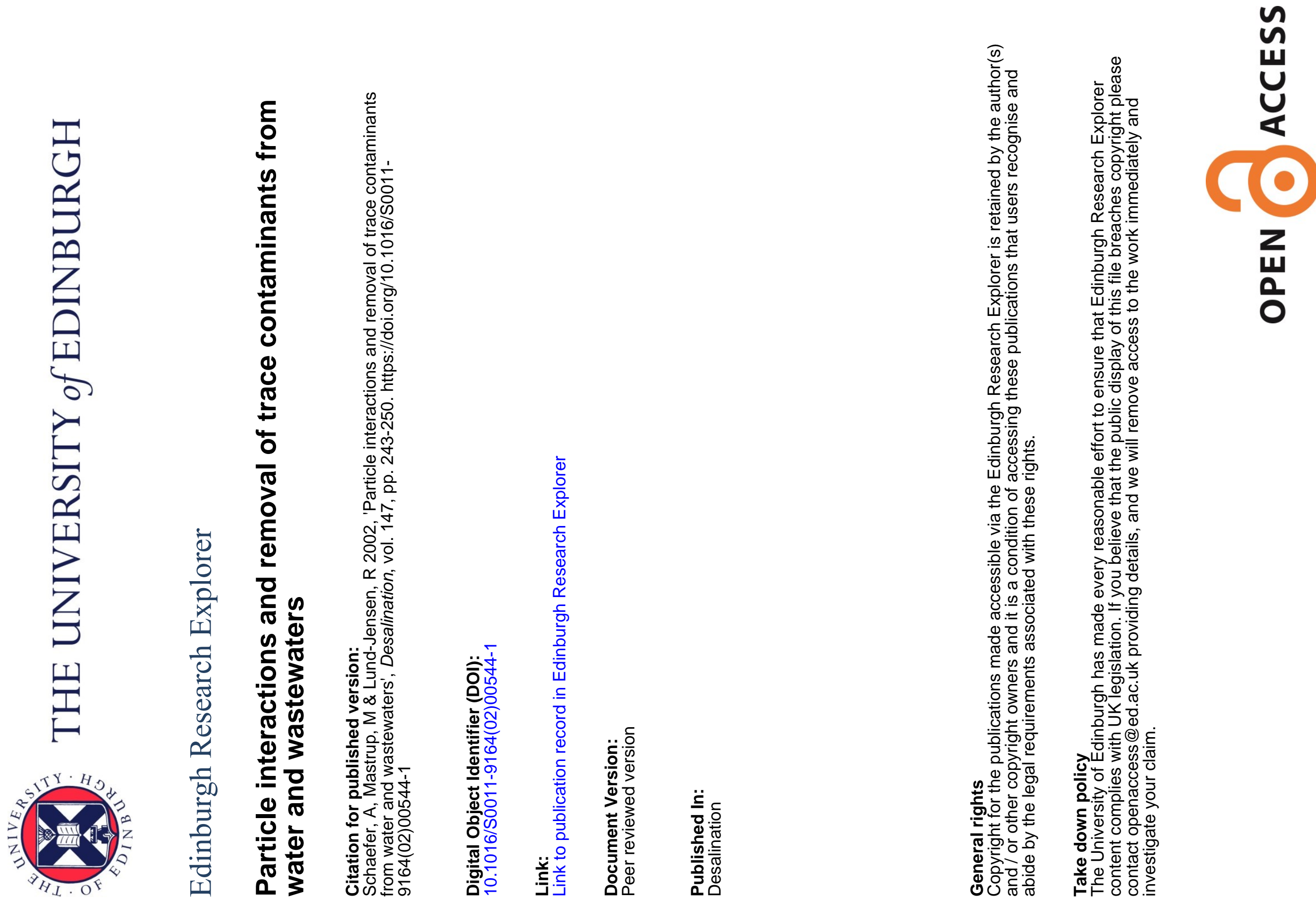
Schäfer, A.I. ; Mastrup, M. ; Lund-Jensen R. (2002) Particle interactions and removal of trace contaminants from water and wastewaters, Desalination 147, 243-250 doi:10.1016/S0011-9164(02)00544-1

\section{Particle Interactions and Removal of Trace Contaminants from Water and Wastewaters}

A.I. Schäfer ${ }^{1}$, M. Mastrup ${ }^{1,2}$, R. Lund Jensen ${ }^{1,2}$

'Centre for Water and Waste Technology, Civil and Environmental Engineering, The University of New South Wales, SYDNEY NSW 2052, AUSTRALIA

ph ++61 29385 4470, fax ++61 29385 6139, A..Schaefer@unsw.edu.au

http://www.cwwt.unsw.edu.au/membrane/homepage.htm

${ }^{2}$ Ingeniørhøjskolen Odense Teknikum, Niels Bohrs Alle 1,5230 Odense M, DENMARK

ph ++4563140300 lok. 478, fax ++4563140474, maibritt@student.unsw.edu.au,

studingbixen@hotmail.com

\section{ABSTRACT}

The adsorption of trace contaminants on natural particles is of great interest as this adsorption enhances the possibility of removing these with low pressure filtration such as MF and UF. This study shows that not organic and inorganic. Experiments have shown that the adsorption capacity of organics is a factor of 10 higher than for inorganics. Ultrafiltration of a solution containing NOM and estrone also indicated this adsorption as the retention of estrone showed strong relationship to the concentration of organic material in the permeate. For practical application of this finding it was investigated if it applied to activated sludge. It was found that activated sludge does adsorb the natural hormones and that activated sludge during ultrafiltration develops a dynamic membrane which enhances the retention of the hormones.

\section{KEYWORDS}

Ultrafiltration, natural hormones, endocrine disrupter, natural organic matter, water recycling, membrane filtration.

\section{INTRODUCTION}

The fate of trace contaminants such as endocrine disrupters or pharmaceuticals in the environment and in wastewater treatment plants is largely dependent on particle-contaminant interactions. In natural systems such as rivers and lakes, trace contaminants, which are associated with colloids settle and accumulate in the sediments. If contaminants are adsorbed onto activated sludge particles, they accumulate in the solid waste of the wastewater treatment plants. If contaminants are dissolved or associated with dissolved natural organics or even stable, unsettlable colloids, they get transported through treatment systems easily.

Where membrane filtration is applied in treatment, such compounds can be removed using nanofiltration $(\mathrm{NF})$ or reverse osmosis (RO) and subsequently accumulate in the concentrate. Microfiltration (MF) and ultrafiltration (UF) are not expected to remove these dissolved contaminants after initial adsorption is complete. While the adsorption can remove considerable amounts of contaminants, saturation leads to breakthrough.

However, the presence of particulates, which adsorb such contaminants can significantly increase the However, the presence of particulates, which adsorb such contaminants can significantly increase the
potential of MF and UF to remove trace contaminants. Two different types of particles may vary this pre-adsorption and hence removal; (I) naturally occurring particles and (II) chemicals added as a pretreatment option.

Category I particles are naturally occurring organic and inorganic colloids, bacteria, activated sludge, cellulose and clays. Category II particles encompass coagulants such as alum or ferric chloride, powdered activated carbon and ion exchange resins.
This paper focuses on category I particles and solutes such as natural organic matter, humic substances, clays bentonite and kaolin, hematite as well as activated sludge. Adsorption isotherms are determined for natural hormones and for some compounds membrane filtration experiments presented.

\section{BACKGROUND}

In recent years there has been increasing evidence of some chemicals (some of which occur naturally) having endocrine modulating characteristics. According to the European Union, an endocrine disrupter is defined as "an exogenous substance that causes adverse health effects in an intact organism, or its progeny, secondary to changes in endocrine function" [1]. It is believed that the disrupting effect of those chemicals on the endocrine system of fish and some mammals may also affect humans.

The group of compounds contains both synthetic and natural occurring chemicals such as nonylphenols, phthalic esters, PCB's, dioxins, phytoestrogens and human estrogens [2]. The human estrogens, mainly estrone, estriol and $17 \beta$-estradiol, are excreted by both males and females in urine and faeces. They are excreted in a conjugated form that makes them virtually inactive as hormones but and faeces. They are excreted in a conjugated form that makes them virtually inactive as hormones but
much more polar, and therefore water soluble [3]. Studies have shown that the hormones are cleaved in the Sewage Treatment Plant (STP) because the microorganisms (such as Escherichia coli) seem to present the enzymes to deconjugate estrogen glucuronides and the hormones then become hydrophobic and reactivated [4].

In current wastewater treatment systems such hormones are not removed completely [5] and are therefore discharged into rivers and the sea. This is where effects on wildlife are observed and much research is dedicated on how to prevent the hormones from being discharged. The removal efficiency of current wastewater treatment facilities such as activated sludge treatment, depends on how much the wastewater solids can adsorb and how quickly mictoorganisms tend to degrade these contaminants. This paper will deal with the question of adsorption rather

Interactions between trace contaminants such as natural hormones and bulk oroanics such as natural organic matter or humic substances and activated sludge are not well understood. Ohlenbusch et al. [6] showed that the interaction between phenolic compounds and natural organic matter (NOM) depends on the characteristics of both the contaminant and the NOM. Depending on the polarity of the compounds hydrophobic and specific interactions could occur. Interactions increased with both the molecular weight and hence the ability of a NOM molecule to form hydrophobic cavities and the number of functional groups and hence the ability to facilitate specific interactions.

Adsorption kinetics and isotherms were measured for the hormones at very low concentrations which are observed in wastewaters to describe the relationship between the concentration in the fluid phase and the concentration in the absorbent particles at a given temperature [7]. In experiments with wastewater Fürhacker et al. [8] showed minimal adsorption with $17 \beta$-estradiol. This ladder finding clearly contradicts the previous statement by Jurgens et al. [3] that hydrophobic pollutants tend to accumulate in those materials with the highest organic content as well as results obtained in this study.

\section{MATERIALS AND METHODS}

\subsection{Chemicals}

Radiolabelled estrone-2, 4,6,7- ${ }^{3} \mathrm{H}(\mathrm{N})$ and estradiol-2, 4,6,7- ${ }^{-} \mathrm{H}(\mathrm{N})$ were purchased from Sigma-Aldrich (Saint Louis, Missouri, USA). All other chemicals were purchased as analytical grade form Ajax Chemicals, Australia. Each experiment was carried out in $100 \mathrm{~mL}$ Erlenmeyer flask containing $50 \mathrm{~mL} 1$ Chemicals, Australia. Each experiment was carried out in $100 \mathrm{~mL}$ Erlenmeyer flask containing $50 \mathrm{~mL} 1$
$\mathrm{mM} \mathrm{NaHCO}$ indicated.

\subsection{Analytical}

Estrogen concentrations were measured using a Packard Instruments scintillation counter.

The following methods were used for particle characterisation; a Olympus BH-2 Light Microscope with Universal Illumination system, for the examination of specimens using incident reflected light, polarised light and dispersion staining. The microscope was equipped with a filar micrometer for measurement of particle and fibre size and a DP12 Digital Camera System. A streaming current detector (SCD), Milton 
Schäfer, A.I. ; Mastrup, M. ; Lund-Jensen R. (2002) Particle interactions and removal of trace contaminants from water and wastewaters, Desalination 147, 243-250 doi:10.1016/S0011-9164(02)00544-1

Roy model SC 4200 supplied by PRYDE Measurement Pty Ltd in Australia, was used to determine the surface current of activated sludge particles. To measure the organic carbon content of the permeates a total organic carbon analyzer SHIMADZU TOC-5000A was used.

\subsection{Membrane filtration}

Stirred cells were used for membrane filtration experiments. Such systems were characterised in detail elsewhere [9].

Filtration Protocol

Prior to each experiment $1 \mathrm{~L}$ of milliq water was filtered through the membrane to remove the glycerin coating and other contaminants. The experimental solution was then filled into the reservoir, and a pressure of 3 bar was applied (compressed instrument air from the bottle). Three times $15 \mathrm{~mL}$ samples of permeate, measured on a balance, was taken, and the experiment terminated. The membranes were used up to 5 times and stored in milliq water in a fridge.

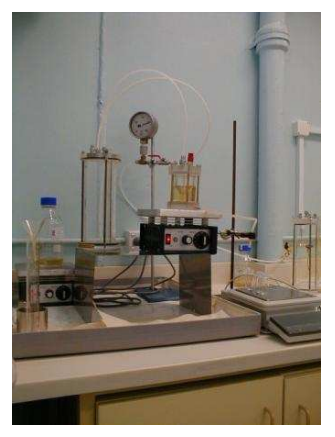

Figur 1 The filtration setup

3.4 Activated Sludge Adsorption

A Bioline (Sydney, Australia) shaking incubator was used for the adsorption studies. In each experiment using activated sludge as the test substance, the sludge from Brendale Sewage Treatment Plant was concentrated by settling in Imhoff cones. Knowing the density and the dry content of the sludge it was possible to calculate the dy content of sludge particles in the different dilutions. Except the experiment with different sludge concentrations, the concentration used throughout all the experiments was $0.27 \mathrm{~g}$ $\mathrm{SS} / 50 \mathrm{~mL}$ buffer solution. Solutions of estrone or $17 \beta$-estradiol concentrations of 1, 5, 10, 50, 100 and $500 \mathrm{ng} / \mathrm{L}$ were prepared and settled particles were added to the Erlenmeyer flasks in different concentrations and $\mathrm{pH}(2,3,4,5,8,11$ and 12). The flasks were shaken for 48 hours and $5 \mathrm{~mL}$ sample were taken with single use syringes after 2 hours, 4 hours, 24 hours and after 48 hours. The $5 \mathrm{~mL}$ samples were centrifuged for $10 \mathrm{~min}$. $(3000 \mathrm{rpm})$ to remove the activated sludge (filtration was not possible due to the retention of estrogens by the membrane deposit) and $1.0 \mathrm{~mL}$ sample was taken from the supernatant.

\section{RESULTS AND DISCUSSION}

\subsection{Activated sludge characterisation}

In the following sections the chemistry effects on the adsorption of estrone and $17 \beta$-estradiol to activated sludge, bentonite, hematite and cellulose are described. To understand the adsorption mechanism, it is essential to charactrerise the activated sludge. The sludge was kept in the refridgerato for an extended period of time and it is assumed that the sludge was mostly decomposed to organic matter. This is important as the objective of this study was to examine adsorption rather than a combined adsorption and degradation effect. Further studies are needed to examine the degradation of such compounds by activated sludge. Figure 2 shows a light micrograph of the sludge, while Figure 3 shows the surface current which is proportional to the surface potential. The activated sludge has a

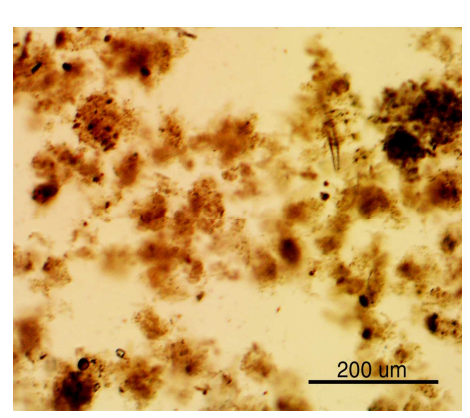

high negative charge at alkaline $\mathrm{pH}$ and a very low negative harge under acidic conditions. This is to be expected given the organic nature of the material.

Figure 2 Light micrograph of activated sludge flocs (the bar in the legend corresponds to $200 \mu \mathrm{m})$.

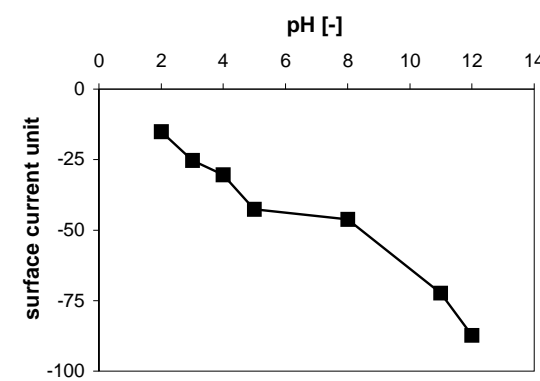

Figure 3 Surface current of activated sludge as a function of $\mathrm{pH}$

4.2 Activated Sludge Adsorption Kinetics

The kinetics of the sorption of hydrophobic compounds like hormones is depending on not only the ad It is gently found to be rapid, and it typically reaches $90 \%$ of equlibium soplion 1 hour [10,11]. This was confirmed in our experiments. Figure 4 s activated sludge as a function of $\mathrm{pH}$. Very interestingly this adsorption is highest at a very low $\mathrm{pH}$ when the charge of the activated sludge is very low. Adsorption is linear within this concentration range of 5 $500 \mathrm{ng} / \mathrm{L}$, which indicates that the adsorption sites are in excess. This is to be expected at such low concentrations of natural hormones. The concentration range selected is similar to concentrations reported in sewage treatment works. As shown in Figure 5, adsorption is also a linear relationship with sludge concentration.

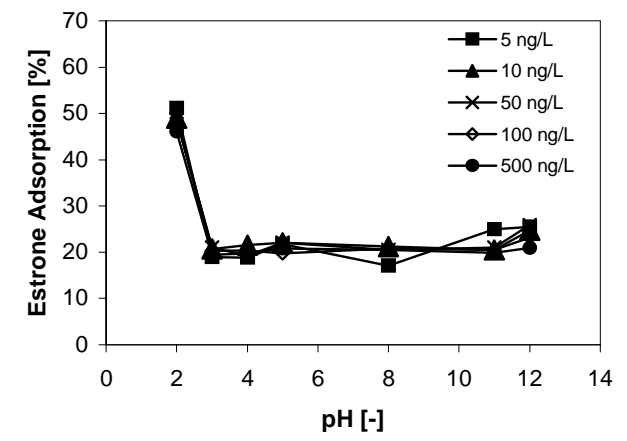

Figure 4 Adsorption of Estrone on Activated Sludge as a function of $\mathrm{pH}$ ( $100 \mathrm{ng}$ estrone/L and sampled after $24 \mathrm{~h}$ ) 
Schäfer, A.I. ; Mastrup, M. ; Lund-Jensen R. (2002) Particle interactions and removal of trace contaminants from water and wastewaters, Desalination 147, 243-250 doi:10.1016/S0011-9164(02)00544-1

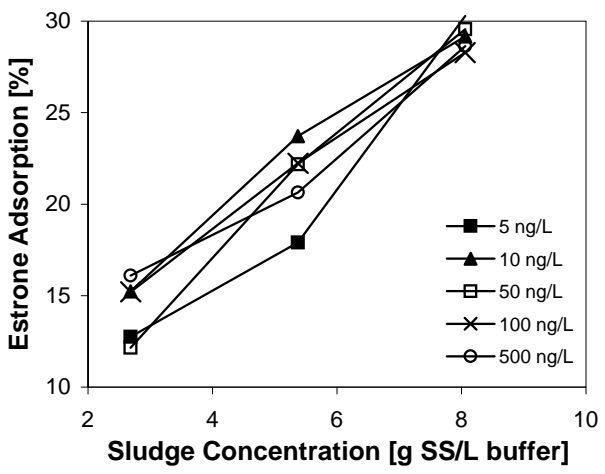

Figure 5 Estrone Adsorption on activated sludge as a function of sludge concentration $(\mathrm{pH} 8$, $1 \mathrm{mM} \mathrm{NaHCO}$ )

\subsection{Adsorption of natural Hormones on Membranes}

Membranes adsorb trace contaminants. This has been shown for microfiltration [12] and nanofiltration and reverse osmosis [13] for those contaminants in question. The same was the case for ultrafiltration membranes and choice of a hydrophilic regenerated cellulose membrane has significantly reduced this membranes
adsorption.

The experiment showed that even those hydrophilic membranes which were selected for this study The experiment showed that even those hydrophilic membranes which were selected for this study
adsorb some of estrone within the first $15 \mathrm{~mL}$ filtered where after the retention becomes stable. In consequence, at least $30 \mathrm{~mL}$ were filtered in experiments before a sample was taken. The retention of estrone increases as the pore size decreases. Based on molecular weight, radii of estrone can be estimated to be $0.84 \mathrm{~nm}$ while the average pore radii is $0.94 \mathrm{~nm}$ for the $1000 \mathrm{Da}$ membrane [9]. This can be explained with the fact that the membranes do not have completely uniform pores and the cut off of those membranes were determined with dextran, so some molecules may be entrapped in pores.

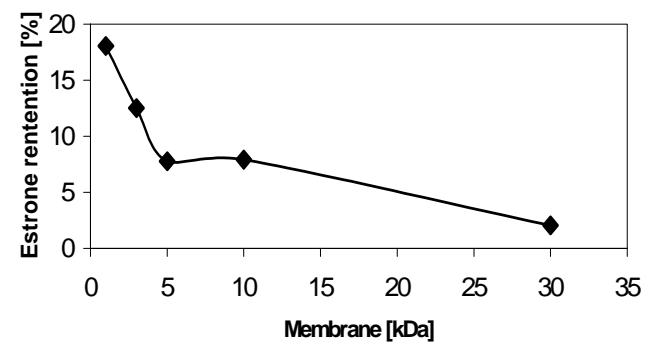

Figure 6 Adsorption of estrone on ultrafiltration membranes

4.4 Estrone Interactions with Natural Organic Matter

The experiments showed that there is a strong relationship between organic content of the permeate and concentration of estrone. From Figure 7 it can be seen that the estrone retention increases with decreasing pore size, which indicates that the estrone has partitioned with the organics and thereby been removed as the solution is filtered.

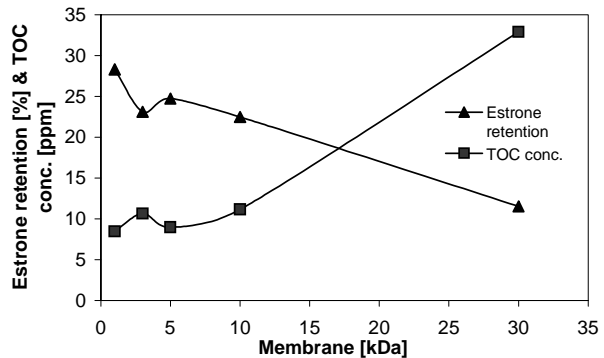

Figure 7 Retention of estrone and NOM content of permeate as a function of membrane size

\subsection{Effect of NOM on adsorption of estrone to particles}

Natural organics may also change the interactions of estrone with particles as shown in Figure 8 with the example of hematite which was exposed to estrone in the absence of organics and in the presence of three types oforganics, IHSS humic acid (HA), IHSS fulvic acid (FA) and natural oirganic matter. The natural organics very clearly enhance the adsorption, presumably due to the interaction between estrone and the adsorbed natural organics.

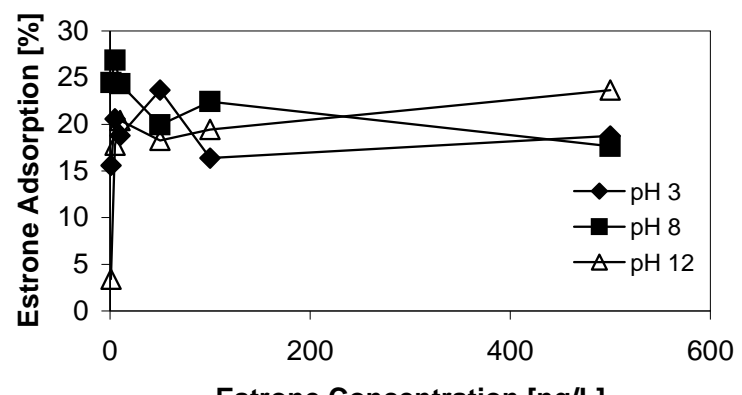

Estrone Concentration [ng/L]

Figure 8 Adsorption of estrone to hematite as a function of estrone concentration and $\mathrm{pH}(10$ $\mathrm{mg} \mathrm{NOM} / \mathrm{L}$ and $10 \mathrm{mg}$ hematite/L, sampled after $4 \mathrm{~h}$ )

As seen in Figure 8, the average estrone adsorption is $\sim 20 \%$, while without adding $10 \mathrm{mg} / \mathrm{L} \mathrm{NOM}$, it would only be $0-5 \%$ (results not shown) 
Schäfer, A.I. ; Mastrup, M. ; Lund-Jensen R. (2002) Particle interactions and removal of trace contaminants from water and wastewaters, Desalination 147, 243-250 doi:10.1016/S0011-9164(02)00544-1

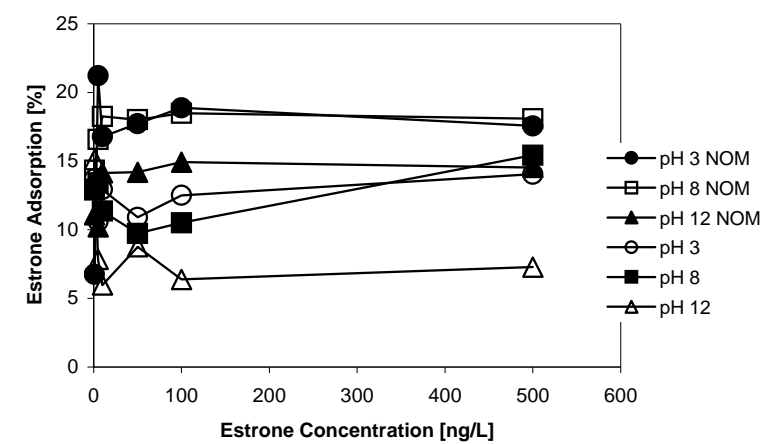

Figure 9 Adsorption of estrone to kaolin as a function of estrone concentration and $\mathrm{pH}(10 \mathrm{mg}$ NOM/L and $100 \mathrm{mg}$ kaolin/L, sampled after $4 \mathrm{~h}$ )

Figure 9 shows the effect of NOM of adsorption of estrone to kaolin. As can be seen, the adsorption is higher with the NOM than without. Between $\mathrm{pH} 12$ with and without NOM, there is a difference in adsorption of $\sim 10 \%$. All those effects influence the membrane filtration of waters and wastewaters which contain trace contaminants, particles and organic matter or even activated sludge in membrane bioreactor applications.

\subsection{Membrane Deposit Effect on Retention of Estrone by Membranes}

Estrone was spiked to various matrices of interest in our research in the area of water recycling. Results are shown in Figure 10. While estrone retention drops as expected with increasing molecular weight cut off of the UF membranes, it was observed that estrone retention is higher in the presence of organics. Raw sewage, secondary effluent and a mixture of natural organics show very simila behaviour. This reduced recention a large pore size is not the case for activated sludge. Retention for pore this matix increses wh por size and hence (to overcome this problem ( (esults not shown). It is evident that the membrane deposit retains estrone. As the pore size increases, the flux increases (as these experiments were conducted in constant pressure filtration) and hence the deposit is more compact at higher pore size and hence retention increases.

Implications of this result are important for applications such as membrane bioreactors (MBRs) where MF or UF membranes are used to extract water from the activated sludge tank. When such a dynamic deposit forms a higher retention than expected may be observed. The choice of membrane and operation condition like flux will impact on this retention.

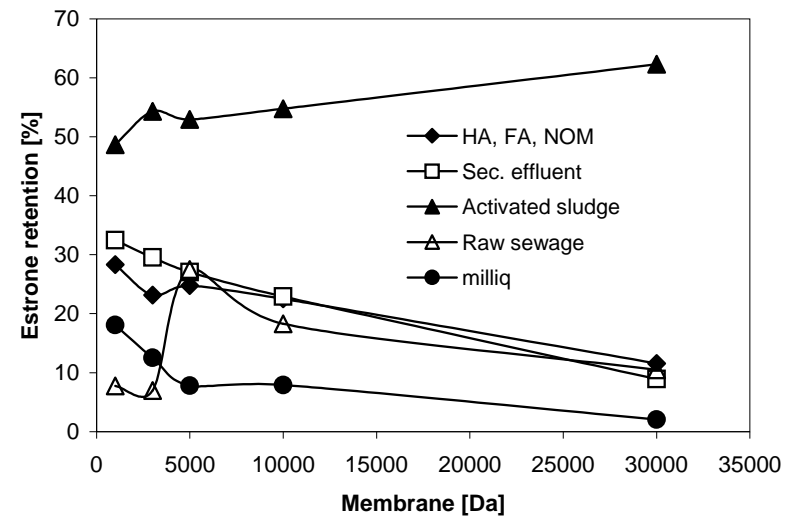

Figure 10 Membrane filtration of different matrices in water recycling spiked with estrone (100ng/L)

4.7 Comparison of Adsorption and Interaction of Estrone with other Category I Particulates

Adsorption to particulates describes the higher affinity of the trace contaminant to the particle surface as compared to water [14]. In this section the results described above are compared to other natural particulates such as cellulose (the major component of toilet paper), clays like Kaolin and Bentonite and pematite, a model colloid, monodispersed spherical iron oxide particle.

Table 1 Interactions of Estrone with Category I particulates ( $\mathrm{pH}$ 7-8, $100 \mathrm{ng} / \mathrm{L}$ estrone, $1 \mathrm{mM}$ $\mathrm{NaHCO}_{3}, 24 \mathrm{~h}$ of adsorption)

\begin{tabular}{lcccc}
\hline Particle & $\begin{array}{c}\text { Average Particle } \\
\text { Diameter } \\
{[\mu \mathrm{m}]}\end{array}$ & $\begin{array}{c}\text { Concentration } \\
{[\mathrm{g} / \mathrm{L}]}\end{array}$ & $\begin{array}{c}\text { Estrone } \\
\text { Adsorption } \\
{[\%]}\end{array}$ & $\begin{array}{c}\text { Estrone } \\
\text { Adsorption } \\
{\left[\mathrm{ng} / \mathrm{g}^{*}\right]}\end{array}$ \\
\hline Hematite & 0.075 & $6.3 \cdot 10^{-3}$ & 0.74 & 150.64 \\
Kaolin & 9 & 0.1 & 8,87 & 140,46 \\
Bentonite & 8 & 0.1 & 13.53 & 175.84 \\
Cellulose & 20 & 0.1 & 8.35 & 113.96 \\
NOM/HS & - & $10 \cdot 10^{-3}$ & 17.50 & 1750 \\
Activated & - & 5.4 & 22.38 & 6.15 \\
Sludge & & & &
\end{tabular}

The implications of results compared in Table 1 are that trace contaminants partition onto different The implications of interactions are interactions are strongly dependent on the concentration of particles in the aqueous systems and the characteristics of those particles. There is a very strong need to determine partitionning coefficients under the conditions as found in the environment of interest.

\section{CONCLUSIONS}

The results indicate that particle - contaminate interactions are critical for trace contaminant removal in water and wastewater treatment. Particles like activated sludge not only act like adsorbents but also like a dynamic membrane or a self rejecting layer. 
Schäfer, A.I. ; Mastrup, M. ; Lund-Jensen R. (2002) Particle interactions and removal of trace contaminants from water and wastewaters, Desalination 147, 243-250 doi:10.1016/S0011-9164(02)00544-1

\section{ACKNOWLEDGEMENTS}

The authors would like to thank Ingenioer Jens Jespersens Fond and IDA's Laane- og Hjaelpefond for providing grants to Maibritt Mastrup and Rikke Lund Jensen. Also a big thank to Reinholdt W. Jorck og Hustrus Fond for providing a grant to Maibritt Mastrup and Otto Moensteds Fond for providing a grant to Rikke Lund Jensen. The Queensland Government and the Australian Research Council are thanked for project funding.

\section{REFERENCES}

[1] J. K. Fawell, D. Sheahan, H. A. James, M. Hurst, S. Scott, Oestrogens and oestrogenic activity in raw and treated water in severn trent water, Water Research 35 (2001), 1240-1244.

T. A. Ternes, M. Stumpf, J. Mueller, K. Haberer, R.-D. Wilken, M. Servos, Behaviour and occurrence of estrogens in municipal sewage treatment plants - I. Investigations in Germany, Canada and Brazil, The Science of the Total Environment 225 (1999), 81-90.

[3] M. D. Jurgens, R. J. Williams, A. C. Johnson, Environment Agency, Bristol, UK, 1999.

[4] T. A. Ternes, P. Kreckel, J. Mueller, Behaviour and occurrence of estrogens in municipal sewage treatment plants - II. Aerobic batch experiments with activated sludge, The Science of the Total Environment 225 (1999), 91-99.

[5] A. C. Johnson, A. Belfroid, A. Di Corcia, Estimating steroid oestrogens inputs into activated sludge treatment works and observations on their removal from the effluent, The Science of the Total Environment 256 (2000), 163-173.

[6] G. Ohlenbusch, M. U. Kumke, F. H. Frimmel, Sorption of phenols to dissolved organic matter investigated by solid phase microextraction, The Science of the Total Environment 253 (2000), 63-74.

[7] W. L. McCabe, J. C. Smith, P. Harriott, Unit Operations of Chemical Engineering McGrawHill: Boston, 2001.

[8] M. Fürhacker, A. Breithofer, A. Jungbauer, 17ß-Estradiol: Behaviour during waste water analyses, Chemosphere 39 (1999), 1903-1909.

[9] A. I. Schäfer, Natural Organic Matter Removal using Membranes: Principles, Performance and Cost Technomic: Lancaster, 2001.

[10] T. C. Voice, J. W. J. Weber, Sorption of Hydrophobic Compounds by Sediments, Soils and Suspended Solids - I, Water Research 17 (1983), 1433-1441.

[11] J. W. J. Weber, T. C. Voice, M. Pirbazari, G. E. Hunt, D. M. Ulanoff, Sorption of Hydrophobic Compounds by Sediments, Soils and Suspended Solids - II, Water Research 17 (1983), 1443-1452.

[12] S. Chang, T. D. Waite, A. I. Schäfer, A. G. Fane, Adsorption of trace steroid estrogens to hydrophobic hollow fibre membranes, Desalination (submitted) (2002),

[13] A. I. Schäfer, L. D. Nghiem, T. D. Waite, Removal of Natural Hormone Estrone from Water and Wastewater using Nanofiltration and Reverse Osmosis, Environmental Science \& Technology submitted)

[14] V. L. Snoevink, R. S. Summers, in Water Quality and Treatment - A Handbook of Community Water Supplies McGraw-Hill Inc,, New York, 1999, 